\title{
The Endeavour Extranet: Building and Managing a B2B e-Community in the British and Irish Leisure Travel Industry
}

\author{
P. Alford and K. Kärcher
}

\begin{abstract}
Endeavour is a business-to-business (B2B) extranet in the British and Irish leisure travel industry. It provides business critical information and reservation functionality for independent high-street travel agents, call centres, and home workers, enabling them to add new values in face of tough competition from vertically integrated tour operator groups and new direct-to-consumer channels such as the Internet and interactive digital television. This case study investigates the evolution of this 'e-community', including some of the challenges faced and lessons learnt while building it.
\end{abstract}

\section{Introduction}

Travel businesses throughout the world are realising the opportunities which Internet technologies bring. However, it appears that the majority of these businesses are looking for ways of integrating the Internet and other business-to-consumer (B2C) channels with their existing processes, as opposed to reinventing themselves as 'DotCom' businesses. Only a few organisations have taken the step of using this technological change to improve their business processes and add new values for their customers.

Online commerce communities, which link businesses with their suppliers, buyers and partners, are creating exciting new e-business and added-value opportunities (Kärcher, 1997; Wells and Woods, 2000). This paper investigates the development of such an online business-to-business (B2B) trading community, or 'e-community', in the travel industry.

\section{The Significance of B2B e-Commerce}

As shown in Figure 1, the growth of B2B e-commerce is predicted to be ten times greater than B2C ecommerce, with the B2B market growing to almost US $\$ 300$ billion by 2002 according to one source.

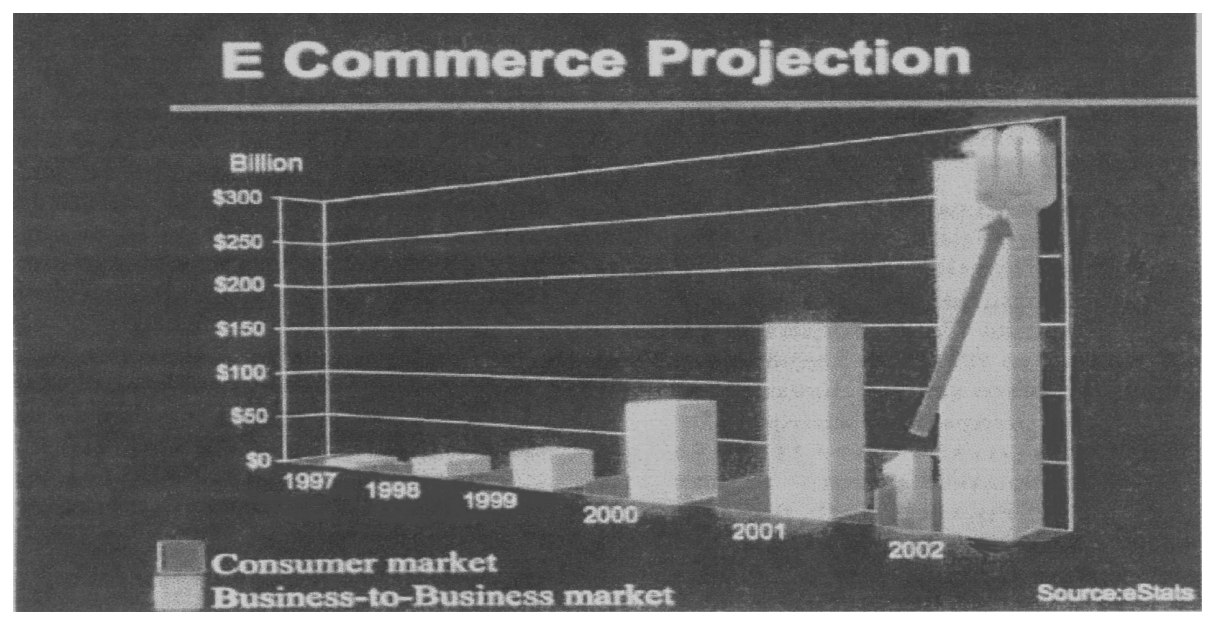

Figure 1. e-Commerce Growth Forecast 
Despite this predicted growth, Timmers (2000) observed that few e-commerce books deal with B2B ecommerce despite the fact that this is estimated to represent around 80 per cent of total e-commerce. While Standing et al.'s (1998) study of travel agents' use of the World Wide Web in Australia had a B2C focus, their study does provide some interesting insights to support a B2B study. They found that very few agencies were using the web as an opportunity to re-engineer their business. 92\% of travel agents ".. chose to view the potential adoption of the Web technology as an add-on to their existing systems rather than something that required a radical re-think of the organisational processes" (p. 42). "Only $8 \%$ classed their [WWW] approach as an enterprise wide examination of the business processes" (p. 41).

Olivier's (1998) study of travel agency extranets also has a B2C focus, although in distinguishing between extranets and intranets he does refer to the potential advantages of travel suppliers participating in an agency extranet. These include accessing an agency database in order to be able to profile an agency's clients and drawing down important management information such as sales figures, commissions earned and agent performances. Therefore, Olivier touches briefly on the advantages to be gained from fostering B2B relationships, and also highlights the potentially powerful position that an agent occupies in the value chain through ownership of customer data.

\section{Methodology}

With this paper, the authors aim to address some of this literature imbalance by investigating how travel agents are re-engineering their businesses through participation in a managed B2B extranet. The authors use 'Endeavour' as a case study to address this issue. Endeavour is one of two major trade portals serving the leisure travel agency community in the UK and Ireland. It is an information and reservation portal targeted at independent high-street travel agents, call centres and home workers. It manages an ecommunity incorporating retailers, tour operators and principals. The case study investigation takes as its starting point a paper by Edwards et al. (1998), which described the structure of the Imminus Travel and Tourism Intranet (later absorbed into Endeavour), and which set out a vision of the future of B2B travel marketplaces.

The study traces the development of this online community and aims to explain how technology is facilitating the change of business processes in the industry. Yin $(1994$, p. 6) states that "how and why questions are more explanatory and likely to lead to the use of case studies, histories, and experiments as the preferred research strategies. This is because such questions deal with operational links needing to be traced over time, rather than mere frequencies or incidences." The Endeavour case study is developed through primary research and draws on business plans, records of meetings, and key informant interviews (also Alford, 2000, pp. 60-65).

\section{IP Viewdata}

Viewdata (the British version of Videotext) has been the principal technology for electronic package holiday distribution in Britain and Ireland for almost two decades and remains so today. Over the last few years, Telewest Imminus controlled an estimated 50\% of the on-line holiday reservations market in Britain, linking approximately 150 tour operators and principals to half of the UK's travel agency community.

As Viewdata has served the travel trade successfully for around 20 years, making sure 'the baby wasn't thrown out with the bath water' was a key consideration in the development of the Endeavour project. This issue also highlights the importance of introducing new information and communication technology 
(ICT) initiatives over a scaled period of time and concentrating on 'quick wins' to make the case for return on investment.

In the past, Viewdata has been distributed via X.25 networks operated by Telewest Imminus ('Fastrak'), by NTL X-Tant ('Istel') and, during the 1980s, by Prestel (Inkpen, 1998, pp. 283-313). In 1997, Telewest Imminus introduced the concept of 'IP Viewdata', where Viewdata is distributed using the Internet Protocol (IP). Figure 2 shows the front-pages of 'Fastrak' IP Viewdata (launched in 1997) and the Endeavour version 'Fastrak 2000' (launched in late 1999). NTL X-Tant (Istel) followed suit in 1998.
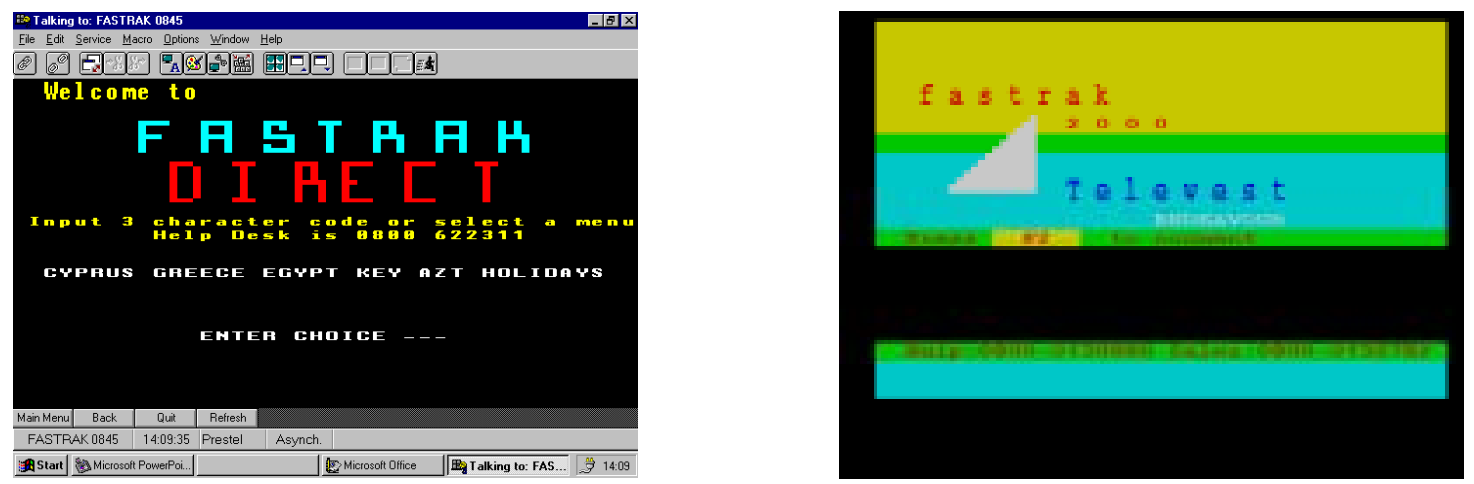

Figure 2. Screen Captures of IP Viewdata 'Fastrak' (left) and 'Fastrak 2000' (right)

As the first step, IP Viewdata enabled the migration of travel agents from X.25 to IP network connectivity. Telewest Imminus achieved this through the development and deployment of proprietary 'IP Network Chameleon' devices, which converted IP to X.25 traffic, and generated Viewdata pages and addressing tables network-centrally. As a result, travel agents were now able to:

- Open multiple viewdata sessions on a single terminal, thus enabling product comparisons for customers

- Enjoy faster Viewdata access speeds

- Access the Internet / World Wide Web at the same time as Viewdata.

For Telewest Imminus it also meant that over 100 dial-up access nodes throughout the UK could be closed during 1997/1998, with only 6 newly built so-called 'Super PoPs' (Point-of-Presence) remaining. This resulted in substantial cost savings and improved service levels since no remote locations had to be maintained.

IP Viewdata also allowed for the provision of a wider choice of travel agent connectivity:

- Dial-up, accessing the service through a local-rate (0845) dial-up on a standard telephone line, or indirect access (IDA) dial-up via a standard BT telephone line with savings on standard BT rates.

- Virtual Leased Line (VLL), providing agents with managed (and unmetered) ISDN access.

- Leased Line (LL), a dedicated, always-on and fully-managed connection, via Frame-Relay kilostreams, megastreams or ADSL (asymmetric digital subscriber line).

Internet access, e-mail, and web-hosting services are being provided in addition.

As the second step, IP Viewdata enabled the migration of host reservation systems of tour operators and principals from X.25 to IP network connectivity. Telewest Imminus aims to achieve this through the development and deployment of a proprietary 'Redirector' system, which is to be launched in early 2001. This 'IP Host Connect' product will, ultimately, result in the closure of the X.25 network. 
Overall, IP Viewdata was essential in providing a technical network platform to support the construction of the Telewest Endeavour e-community (and subsequently the NTL X-Tant 'TravelEye' e-community) based on modern web technologies.

\section{The Endeavour Extranet}

\subsection{The Imminus Travel and Tourism Intranet}

Endeavour is based on a concept prototyped by Imminus, a travel network provider that Telewest acquired in 1998. In 1996, the senior management at Imminus realised there was a need to move away from Viewdata towards a more flexible electronic commerce environment in which travel and tourism companies could trade (Edwards et al., 1998; O'Connor, 1999, pp. 153-158). The proposed solution had a number of benefits linked with managed intranets, in contrast to the Internet, namely security and a guaranteed service level (Jewell et al., 1999). In addition, a crucial advantage was that it allowed for the co-existence of IP Viewdata and Internet-based value added services designed to enable travel companies to migrate to a more sophisticated e-business platform.

Although referred to as an intranet for branding reasons, the proposed solution was an extranet (Meyer, 2000; Slaughter, 2000). Travel agents were able to make more complex bookings electronically (rather than by telephone) and make them faster on a user-friendly interface. This Internet technology was more cost effective than Viewdata, thus enabling tour operators and principals to reduce their distribution costs. In addition, detailed management information in the form of transactional data was provided, thereby realising one of the advantages referred to by Olivier (1998, p. 215).

The Imminus Intranet front-end system was piloted in 1997 (Figure 3) and the first live booking was made on the prototype between the travel agent Apollo Travel and the tour operator Crystal Holidays.
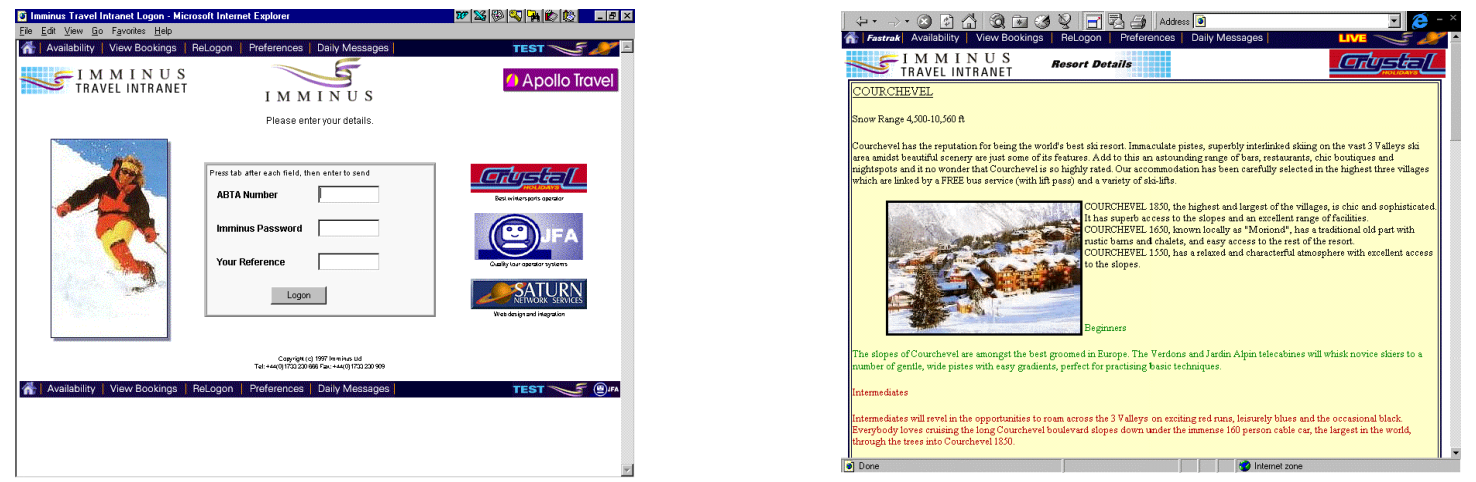

Figure 3. Screen Captures of the Imminus Intranet Front-End System

While the Imminus Intranet front-end prototype proved the concept successfully, its development was not taken further for commercial reasons. Instead, Telewest developed an e-business strategy around an ecommunity portal (Figure 4), with the more complex and costly software developments (such as the Imminus Intranet front-end) forming a later step in the process. 


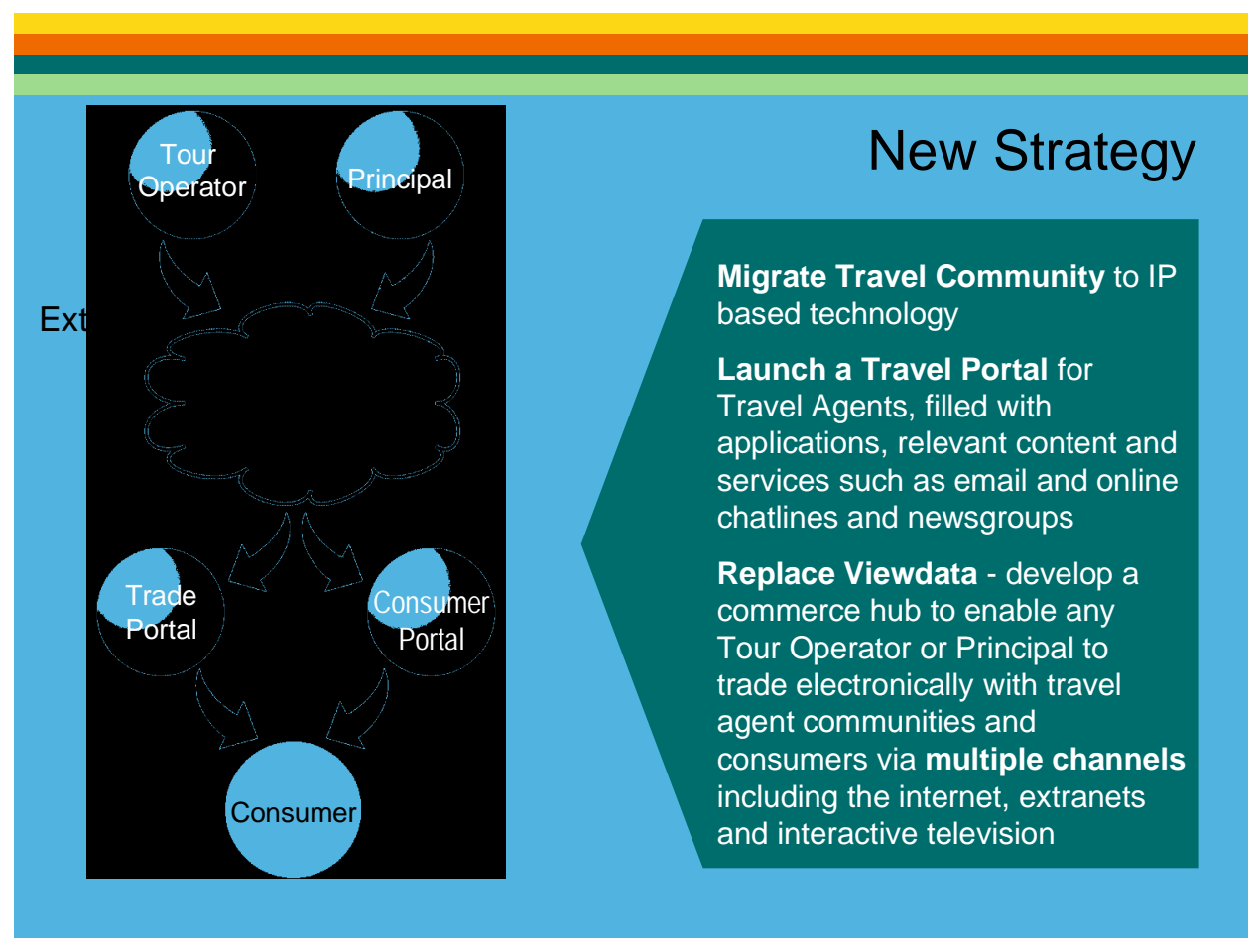

Figure 4. Telewest's Phased e-Business Travel Strategy

\subsection{The Endeavour Extranet - Phase I (November 1999 to September 2000)}

The Endeavour (Phase I) portal was launched in November 1999 (Figure 5).
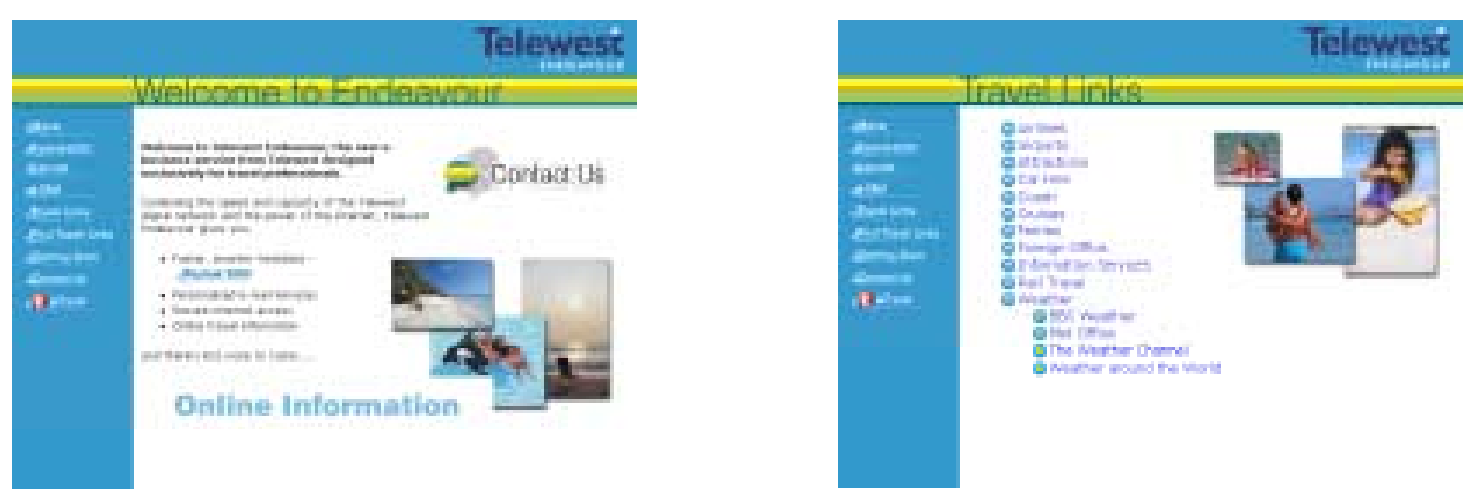

Figure 5. Screen Captures of the Endeavour (Phase I) Portal

The Endeavour portal brought, for the first time, IP Viewdata ('Fastrak 2000'), generic Internet and some specialised travel information services together on a single site, thus creating a 'marketspace portal' (Wells and Woods, 2000, p. 86). It was a scaled approach which was critical for e-business development, helping to ensure that technology is seen as the facilitator of business processes and not vice versa. The findings by Standing et al. (1998) highlight the importance of adopting this incremental approach when 
dealing with a travel agency community. It also proved the Telewest internal business case, which resulted in the approval for substantial further investment.

\subsection{The Endeavour Extranet - Phase II (September 2000 onwards)}

The migration to a new technical platform took place on Monday, 18 September 2000 (Phase II), following an investment of over $£ 4$ million (Figure 6). The Endeavour software and hardware were transported to Telewest's data centre in Knowsley near Liverpool, England, one of Europe's largest data management centres. The required elements of Phase I were integrated into the new Phase II software, which then was implemented on a new Sun Solaris server farm.
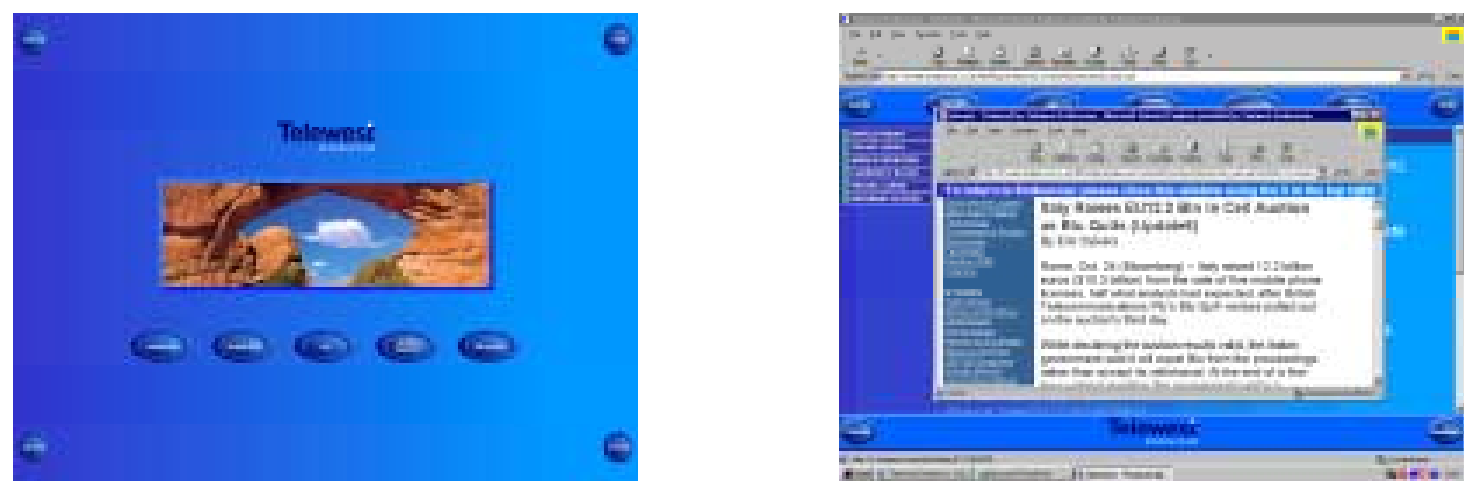

Figure 6. Screen Captures of the Endeavour (Phase II) Portal

The key enhanced features of the Endeavour Phase II service were:

1. Information Centre:

- The latest national and international travel related news, regularly updated throughout the day. The information is presented as a headline from which, through a click of the mouse on the headline, the agent can gather further details.

- Weather reports, from across the world

- Currency and conversion rates updated daily

- Links to relevant travel websites including Foreign Office, Customs \& Excise, passport, visa and health advice, UK airport, car parking, airline facilities, car hire and ferry information.

2. Travel Agent Forum: A message board by which agents can post information, pose questions and join in debates.

3. On-line Tutorial Facility: Providing users with an introduction to Endeavour, as well as information on how to use browsers, 'Fastrak 2000', e-mail features, web hosting and searches.

4. Travel Community Directory: Offering the ability to search and locate agents who specialise in particular areas or products such as ski, cruise and long-haul travel.

5. Web Hosting: Endeavour customers can have a simple web site, hosted on the Endeavour platform including domain name registration, domain name e-mail, and registration with search engines.

6. Access to the Worldspan Global Distribution System (GDS). 


\subsection{The Endeavour Extranet - Future Enhancements}

In December 2000, over 700 travel agency locations were registered Endeavour users, and a further $3,000+$ travel agencies were using 'Fastrak 2000' IP Viewdata. The first-mover advantages created by the launch of IP Viewdata and the subsequent launch of the Endeavour portal resulted in Telewest Imminus overtaking, for the first time in its almost 20 year history, NTL X-Tant (Istel) in market share of on-line leisure travel distribution in the UK. Telewest aims to maintain this position through future enhancements of Endeavour. In particular, value-added services (VAS) and other content will be added on an on-going basis, and ultimately Application Service Provision/Providing (ASP) (Knolmayer, 2000) will be provided.

\section{Outlook: Convergence of technologies and channels}

The Endeavour vision for creating an e-community is essentially one of convergence of technologies and channels, incorporating a central commerce hub (or portal) in which agents and principals can trade. Having achieved a critical mass of content, elements of the commerce hub could be made accessible to the consumer via a number of channels including the Internet, mobile technologies, and Interactive Digital Television (iDTV).

It would not have made commercial sense to create an 'open access' commerce hub on the X.25 legacy platform, and the first step of the Endeavour project has involved replacing this platform with IP technologies. Endeavour has integrated a range of protocols and services including IP Viewdata, IP hosting, integration with Internet, iDTV, Extranet and Intranet. This new platform 'e-enables' the travel trade, presenting them with a number of advantages:

- The transition from a legacy platform to IP has been achieved on a gradual scale to minimise the cost and disruption to travel agencies. Although re-branded as 'Fastrak 2000', agents continue to use character-based Viewdata albeit on an IP platform. There is an important distinction to be made here between the $\mathrm{B} 2 \mathrm{C}$ web sites on the Internet, which require rich multimedia in order to attract the fickle Internet consumer, and the $\mathrm{B} 2 \mathrm{~B}$ 'mission-critical' requirements of the travel agent. Endeavour continues to provide travel agents with a fast and reliable service with which they are familiar.

- The travel agent now has access to a number of services, outlined above, including online training, email, travel industry information, and late availability.

- The legacy system allowed travel agents to use only one booking session. With the move to IP, agents can now undertake multiple booking sessions. This enables travel agents to make optimum use of the telephone line and calls, thereby improving overall cost effectiveness.

- IP enables reservations to be made and information to be exchanged at much faster speeds.

- Agents will not lose any tour operator business, as operators do not have to change their legacy systems to be compatible with the new platform.

- IP facilitates the integration of different platforms including Wide Area Networks (WAN), Local Area Networks (LAN), and protocols including Point-to-Point Protocol (PPP), Post Office Protocol (POP) and Ethernet. This integration presents a number of advantages. For example, it is now possible to achieve seamless integration of the front-office with the back-office. PPP enables a computer to connect with a server via a modem and become an actual node on the Internet. This enables the agent not only to connect from the office, but also remotely say from home or from a customer's location. The PPP link also allows the agent to communicate via e-mail and to browse the Web.

- Potentially the greatest advantage of this integration lies in the opportunities for the convergence of data (Internet), voice (telephone) and video (television). Once the platforms are integrated, then applications can talk to each other. Agents, tour operators and principals can begin to take advantage of open languages such as HTML and Java. 
Having developed the physical IP platform, Telewest is now focusing on the provision of content, and the addition of value-added applications. Ultimately, Viewdata could be replaced with structured messages, including EDI, Interactive EDI and XML. This will enable all community participants to integrate with iDTV, consumer web sites and Internet search engines (Figure 7).

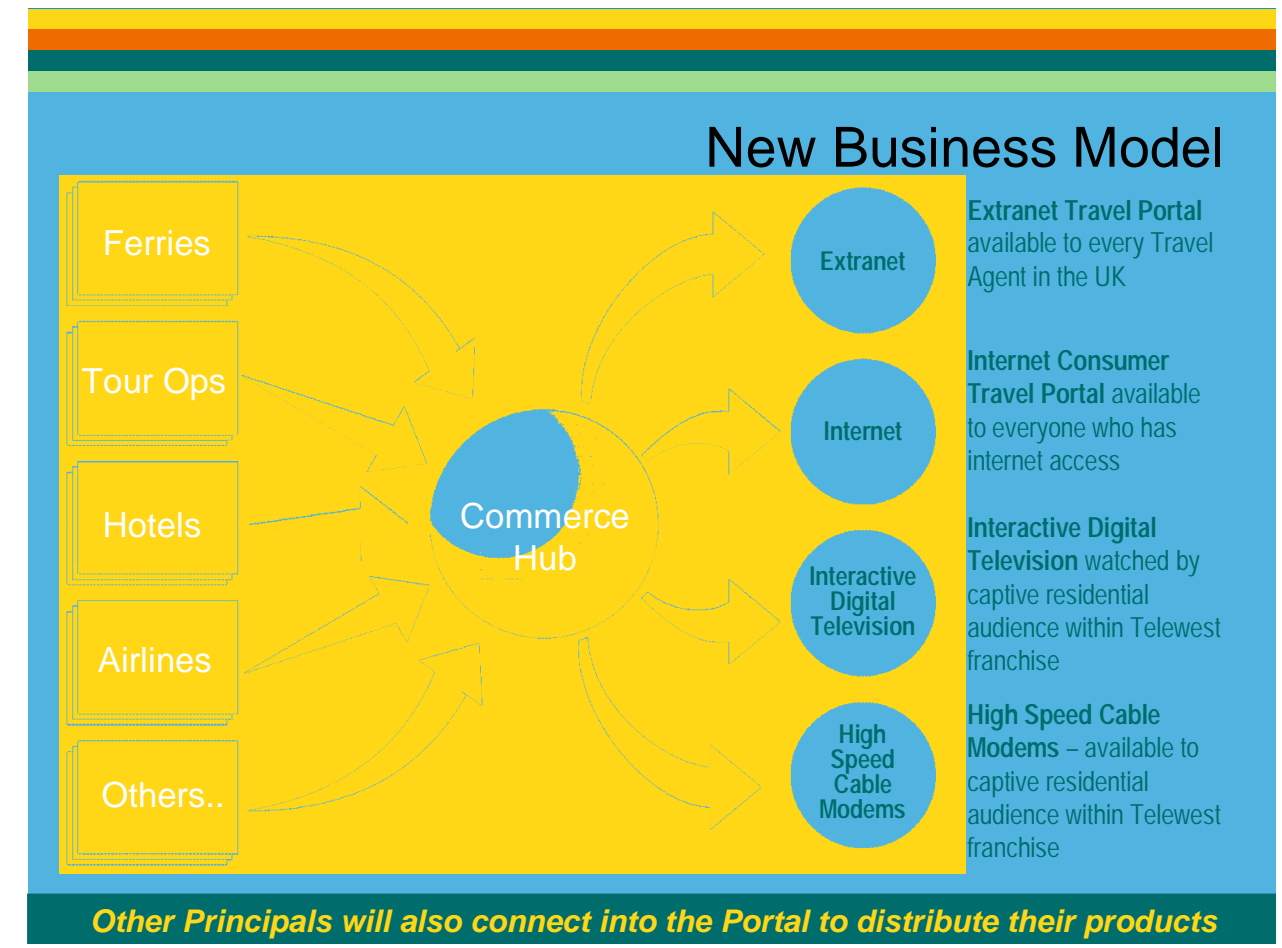

Figure 7. The Telewest Travel e-Community Model

The significant industry and commercial benefits lie in the future when the project has achieved true convergence, and travel agents, tour operators and principals can trade efficiently in a secure and managed e-business environment.

\section{References}

Alford, P. (2000). E-Business in the Travel Industry. Travel and Tourism Intelligence, London, England.

Edwards, G., Dawes, C. and Kärcher, K. (1998). 'The Imminus Travel and Tourism Intranet'. In: Buhalis, D., Tjoa, A.M. and Jafari, J. (Editors). Information and Communication Technologies in Tourism 1998. Springer, New York/Wien, pp. 190-200.

Inkpen, G. (1998). Information Technology for Travel and Tourism (2nd Edition). Addison Wesley Longman Limited, Harlow, Essex, England.

Jewell, G., Williamson, B. and Kärcher, K. (1999). 'The Airtours Cruise Intranet.' In: Buhalis, D. and Schertler, W. (Editors). Information and Communication Technologies in Tourism 1999. Springer-Verlag, Wien, Austria, pp. 337-346.

Kärcher, K. (1997). Reinventing the Package Holiday Business: New information and communication technologies. DUV, Wiesbaden, Germany. 
Knolmayer, G.F. (2000). 'Application Service Providing (ASP).' Wirtschaftsinformatik, 42(5), pp. 443446.

Meyer, K. (2000). 'Building Extranet Communities'. Telecommunications, June, pp. 77-78.

O'Connor, P. (1999). Electronic Information Distribution in Tourism and Hospitality. CABI Publishing, Wallingford, Oxon, England, and New York, USA.

Olivier, A.P.S. (1998). 'The Dissemination of Information by Means of Travel Agency Extranets.' In: Buhalis, D., Tjoa, A.M. and Jafari, J. (Editors). Information and Communications Technologies in Tourism 1998. Springer, New York/Wien, pp. 212-223.

Slaughter, S. (2000). 'Net Gain: Suppliers are communicating more and more directly with corporate clients via extranets.' Business Travel World, October, pp. 48-50.

Standing, C., Vasudavan, T. and Borbely, S. (1998). 'Re-Engineering Travel Agencies with the World Wide Web.' EM - Electronic Markets, 8(4), 40-43.

Timmers, P. (2000). Electronic Commerce: Strategies and models for business-to-business trading. Wiley, New York, USA.

Wells, D. and Woods, E. (2000). 'What's Your Company Policy on Portals?' Telecommunications, October, pp. 85-86, 88, 90.

Yin, R. (1994). Case Study Research: Design and methods (2nd Edition). Sage, London, England.

\section{Acknowledgements}

The authors would like to acknowledge the contributions of Keith Webber (General Manager), Mike Ruck (Product Manager), Adrian Briggs (Technical Project Manager), Sharon Lancaster (Technical Project Manager), Ian Millward (Sales Manager), and Tim White (Consultant) in this project.

\section{About the Authors}

- Philip Alford is Senior Lecturer at Luton Business School, England.

- Dr. Karsten Kärcher is the Strategic Account Director for Travel (and responsible for Strategy and Business Development in the Travel Division) at Telewest Communications PLC, England.

Contact: Karsten.Karcher@genesysinformation.com or http://www.genesysinformation.com.

For further information see also http://www.endeavour.co.uk. 